Pacific Journal of Mathematics

ON SPACES WHICH HAVE A CLOSURE-PRESERVING COVER 


\section{ON SPACES WHICH HAVE A CLOSURE-PRESERVING COVER BY FINITE SETS}

\section{YUKINOBU YAJIMA}

The purpose of the present paper is to give a characterization of spaces which have a closure-preserving cover by finite sets, in terms of hereditary metacompactness and generalized $\sigma$-discreteness. Several results with respect to spaces which have a closure-preserving cover by finite sets can be deduced easily from our characterization. Moreover, we can conclude more easily from it whether or not a given space has such a cover.

1. Introduction. H. Tamano [10] and R. Telgársky [11] raised independently the question of whether or not a space which has a closure-preserving cover by compact sets must be paracompact. H. B. Potoczny [7] showed that even if a space has a closurepreserving cover by finite sets, it is not necessarily paracompact. Thus, the study of spaces which have a closure-preserving cover by finite sets has been taken up by several authors in [9], [11], [12], [13] and [14]. In particular, R. Telgársky [12] gave a necessary condition and a sufficient condition for a given space to have such a cover. But each of these conditions is not necessary and sufficient as we shall show by examples below. In the present paper, we shall first find a necessary and sufficient condition for a topological $T_{1}$-space to have a closure-preserving cover by finite sets. It will be shown that the necessary condition and the sufficient condition of R. Telgársky can be deduced easily from our necessary and sufficient condition. Secondly, we shall prove that it is undecidable under set theoretic assumptions whether or not a first countable normal space with a closure-preserving cover by finite sets is metrizable.

2. Preliminaries and main theorem. Throughout this paper, $N$ denotes the set of all natural numbers and all spaces are assumed to be $T_{1}$-spaces.

A space $X$ is said to be weakly $\sigma$-discrete, if $X$ is the countable union of discrete subsets $\left\{X_{n}: n \in N\right\}$ such that $\bigcup_{i=1}^{n} X_{i}$ is closed in $X$ for each $n \in N$. A space $X$ is said to be $\sigma$-discrete ([12], [13]), if $X$ is the countable union of discrete closed subsets. A space $X$ is said to be hereditarily metacompact, if each (open) subset of $X$ is metacompact.

Our main theorem is as follows. 
THEOREM 1. The following are equivalent for a space $X$.

(a) $X$ has a closure-preserving cover by finite sets.

(b) $X$ is hereditarily metacompact and weakly $\sigma$-discrete.

REMARK. It is easy to see from Theorem 1 that the spaces which are given by examples in [6], [7] and [14] have closurepreserving covers by finite sets.

\section{Proof of Theorem 1.}

LEMma 2. If a space $X$ has an open cover $\mathfrak{H}=\{U(x): x \in X\}$ such that $x \in U(x)$ for each $x \in X$ and $U(x) \subset U(y)$ whenever $x \in U(y)$, then $\widetilde{F}=\left\{F_{x}: x \in X\right\}$ is a closure-preserving cover of $X$, where $F_{x}=$ $\{y \in X: x \in U(y)\}$ for each $x \in X$.

Proof. Since $x \in F_{x}$ for each $x \in X, \widetilde{F}$ is a cover of $X$. Let $Y \subset X$. Let $x \in \overline{\mathrm{U}_{y \in Y} F_{y}}$. Then there is a point $y_{0} \in Y$ such that $U(x) \cap F_{y_{0}} \neq \varnothing$. Choose $z \in U(x) \cap F_{y_{0}}$. Since $U(z) \subset U(x)$ and $y_{0} \in$ $U(z)$, we have $y_{0} \in U(x)$. Hence $x \in F_{y_{0}} \subset \bigcup_{y \in Y} F_{y}$. This proves that the cover $\widetilde{F}$ is closure-preserving.

Let us consider the following two conditions $(*),(* *)$.

Condition (*): $\quad X$ has an open cover $\mathfrak{U}=\{U(x): x \in X\}$ such that (i) $x \in U(x)$ for each $x \in X$, (ii) $U(x) \subset U(y)$ whenever $x \in U(y)$, and (iii) $\mathfrak{u}$ is point-finite in $X$. and

Condition (**): $\quad X$ has an open cover $\mathfrak{B}=\{V(x): x \in X\}$ such that (i) $x \in V(x)$ for each $x \in X$, and (ii) $\mathfrak{Y}$ is point-finite in $X$, and has a countable pairwise disjoint cover $\left\{X_{n}: n \in N\right\}$ such that (iii) each $X_{n}$ is a discrete subset and (iv) $\bigcup_{i=1}^{n} X_{i}$ is closed in $X$ for each $n \in N$.

We shall prove the three lemmas below.

LEMMA 3. The following are equivalent for a space $X$.

(a) $X$ has a closure-preserving cover by finite sets.

(b) $X$ satisfies the condition (*).

Proof. (a) $\rightarrow\left(\right.$ b): Let $\Im=\left\{F_{\alpha}: \alpha \in A\right\}$ be a closure-preserving cover of $X$ by finite sets. Put $U(x)=X-\bigcup\left\{F_{\alpha}: x \notin F_{\alpha}\right\}$ for each $x \in X$ and $\mathfrak{U}=\{U(x): x \in X\}$. It is obvious that $\mathfrak{u}$ satisfies (i) and (ii) of $\left(^{*}\right)$. Assume now that there is a point $x \in X$ such that ord $(x, U) \geqq \aleph_{0}$. We can choose an infinite number of points $x_{1}, x_{2}$, $\cdots \in X$ such that $x \in U\left(x_{n}\right)$ for each $n \in N$. Choose $F_{\alpha} \in \mathfrak{F}$ such that $x \in F_{\alpha}$. Then we have $x_{n} \in F_{\alpha}$ for each $n \in N$. Since $F_{\alpha}$ is finite, this is a contradiction. Hence $\mathfrak{U}$ is point-finite in $X$. 
(b) $\rightarrow$ (a): It is obvious from Lemma 2 and (iii) of $(*)$.

LEMmA 4. For every space $X$, the condition (*) and the condition $(* *)$ are equivalent.

Proof. $(*) \rightarrow(* *)$ : Put $X_{n}=\{x \in X:$ ord $(x, \mathfrak{u})=n\}$ for each $n \in$ $N$. It is obvious that $\left\{X_{n}: n \in N\right\}$ is a countable pairwise disjoint cover of $X$. Since $\bigcup_{i=1}^{n} X_{i}=\{x \in X: \operatorname{ord}(x, \mathfrak{u}) \leqq n\}, \bigcup_{i=1}^{n} X_{i}$ is closed in $X$ for each $n \in N$.

Fix $n \in N$ and $x \in X_{n}$. We can choose distinct $n$ points $x_{1}, \cdots$, $x_{n} \in X$ such that $\left\{x^{\prime} \in X: x \in U\left(x^{\prime}\right) \in \mathfrak{H}\right\}=\left\{x_{1}, \cdots, x_{n}\right\}$. Let $y \in U(x) \cap X_{n}$. By (i) and (ii) of $(*), y \in U(y) \subset U(x) \subset \bigcap_{i=1}^{n} U\left(x_{i}\right)$. Since ord $(y, \mathfrak{u})=n$, $y \in\left\{x_{1}, \cdots, x_{n}\right\}$. Thus $X_{n}$ is a discrete subset of $X$ for each $n \in N$.

$(* *) \rightarrow(*)$ : We use the induction with respect to $n$. Let $P(n)$ be the proposition: There are point-finite (in $X$ ) collections $\mathfrak{u}_{i}=$ $\left\{U(x): x \in X_{i}\right\}$ of open sets for $i=1, \cdots, n$ such that (a) $U(x) \cap X_{i}=\{x\}$ for each $x \in X_{i}$, (b) if $j<i, x \in X_{i}, y \in X_{j}$ and $x \in U(y) \in \mathfrak{H}_{j}$, then $U(x) \subset U(y)$ and (c) $U(x) \subset V(x)$ and $U(x) \cap \bigcup_{j=1}^{i-1} X_{j}=\varnothing$ for each $x \in X_{i}$.

It is obvious that $P(1)$ is true. Assume now that $P(n)$ is true. By (iii) and (iv) of (**), we can choose an open neighborhood $U(x)$ of $x$ for each $x \in X_{n+1}$ such that $U(x) \subset V(x), U(x) \cap X_{n+1}=\{x\}$ and $U(x) \cap \bigcup_{i=1}^{n} X_{i}=\varnothing$. Moreover, if $x \in \bigcup_{i=1}^{n}\left\{U: U \in \mathfrak{H}_{i}\right\} \cap X_{n+1}$, then we choose $U(x)$ such that $U(x) \subset \bigcap\left\{U: x \in U \in \bigcup_{i=1}^{n} \mathfrak{u}_{i}\right\}$. It is possible since $\left\{U: x \in U \in \bigcup_{i=1}^{n} \mathfrak{u}_{i}\right\}$ is a finite collection. Put $\mathfrak{u}_{n+1}=\{U(x)$ : $\left.x \in X_{n+1}\right\}$. By our construction and $P(n)$, it is easy to see that $\mathfrak{H}_{1}, \cdots, \mathfrak{u}_{n+1}$ satisfy the conditions (a), (b) and (c) of $P(n+1)$ and $\mathfrak{u}_{n+1}$ is point-finite in $X$. So, $X$ has an open cover $\bigcup_{n=1}^{\infty} \mathfrak{u}_{n}$ such that $\mathfrak{U}_{1}, \cdots, \mathfrak{u}_{n}$ satisfy the conditions of $P(n)$ for each $n \in N$. Put $\mathfrak{U}=$ $\bigcup_{n=1}^{\infty} \mathfrak{u}_{n}$. By the pairwise disjointness of $\left\{X_{n}: n \in N\right\}, \mathfrak{u}=\{U(x): x \in X\}$. The open cover $\mathfrak{U}$ satisfies (i), (ii) and (iii) of (*).

Lemma 5. The following are equivalent for a space $X$.

(a) $X$ satisfies the condition $(* *)$.

(b) $X$ is hereditarily metacompact and weakly $\sigma$-discrete.

Proof. (a) $\rightarrow(\mathrm{b})$ : It follows from (i) and (ii) of $(* *)$ that $X$ is hereditarily metacompact. $X$ is obviously weakly $\sigma$-discrete.

(b) $\rightarrow$ (a): Let $X=\bigcup_{n=1}^{\infty} X_{n}$ such that $X_{n}$ is a discrete subset, $\bigcup_{i=1}^{n} X_{i}$ is closed in $X$ and $\bigcup_{i=n}^{\infty} X_{i}$ is metacompact for each $n \in N$. We may assume, without loss of generality, $X_{m} \cap X_{n}=\varnothing$ for $m \neq n$. Since each $X_{n}$ is a discrete closed subset in $\bigcup_{i=n}^{\infty} X_{i}$, there is a pointfinite collection $\mathfrak{V}_{n}=\left\{V(x): x \in X_{n}\right\}$ of open sets for each $n \in N$ such that $V(x) \cap X_{n}=\{x\}$ and $V(x) \subset \bigcup_{i=n}^{\infty} X_{i}$ for each $x \in X_{n}$. Put $\mathfrak{B}=$ 
$\bigcup_{n=1}^{\infty} \mathfrak{B}_{n}$. Then $\mathfrak{B}=\{V(x): x \in X\}$. It is easy to prove that $\mathfrak{B}$ is point-finite in $X$. Hence $X$ satisfies the condition (**).

By Lemmas 3, 4 and 5, the proof of Theorem 1 is complete.

\section{Applications.}

LEMMA 6. Each metacompact $\sigma$-discrete space is hereditarily metacompact.

Proof. Let $X$ be a metacompact $\sigma$-discrete space. We may assume, without loss of generality, that $X=\bigcup_{n=1}^{\infty} X_{n}$ such that each $X_{n}$ is a discrete closed subset of $X$ and $X_{m} \cap X_{n}=\varnothing$ for $m \neq n$. Let $Y$ be an open subset of $X$. Let $\mathfrak{u}$ be an open cover of $Y$. Since $X_{n} \cap Y$ is a discrete closed subset of $X$, there is a point-finite (in $X$ ) collection $\mathfrak{B}_{n}=\left\{V(x): x \in X_{n} \cap Y\right\}$ of open sets of $X$ for each $n \in N$ such that $x \in V(x), V(x) \cap \bigcup_{i=1}^{n-1} X_{i}=\varnothing$ and $V(x)$ is a subset of some element of $\mathfrak{u}$ for each $x \in X_{n} \cap Y$. Put $\mathfrak{B}=\bigcup_{n=1}^{\infty} \mathfrak{V}_{n}$. Then $\mathfrak{B}=\{V(x): x \in Y\}$ and $\mathfrak{B}$ is a point-finite open refinement of $\mathfrak{U}$ in $Y$. Hence $X$ is hereditarily metacompact.

COROLLARY 7. Each metacompact $\sigma$-discrete space has a closurepreserving cover by finite sets.

This is an immediate consequence of Theorem 1 and Lemma 6 .

REMARK. R. Telgársky proved in [12] (Theorem 5) that each paracompact $\sigma$-discrete space has a closure-preserving cover by finite sets. Corollary 7 generalizes this result. We shall show in $\S 5$ (Example 3) that there is a metacompact $\sigma$-discrete space which is not paracompact.

Recall that $Y$ is said to be scattered, if each subset $Z$ of $Y$ has an isolated point in $Z$.

CoRollary 8 (R. Telgársky [12]). If $X$ has a closure-preserving cover by finite sets, then $X$ has a countable cover $\left\{Y_{n}: n \in N\right\}$, where $Y_{n}$ is a scattered closed subset of $X$ and it is the union of $n$ discrete subsets for each $n \in N$.

This an immediate consequence of Theorem 1.

CoROLlary 9. The following are equivalent for a space $X$.

(a) $X$ has a closure-preserving cover by finite sets.

(b) $X$ is hereditarily metacompact and has a $\sigma$-closure-pre- 
serving cover by finite sets.

Proof. (a) $\rightarrow$ (b): Obvious.

(b) $\rightarrow$ (a): It is easy to show that the countable union of weakly $\sigma$-discrete closed subsets is weakly $\sigma$-discrete. Hence $X$ is hereditarily metacompact and weakly $\sigma$-discrete.

REMARK. Our Corollary 9 has been proved earlier, in [13] (Theorem 12.1), by R. Telgársky for the case of $X$ being a metrizable space.

THEOREM 10. The following are equivalent for a space $X$.

(a) $X$ has a closure-preserving closed cover by compact sets.

(b) $X$ has an open cover $\mathfrak{U}=\{U(x): x \in X\}$ such that (i) $x \in U(x)$ for each $x \in X$, (ii) $U(x) \subset U(y)$ whenever $x \in U(y)$ and (iii) $C(x)=$ $\{y \in X: x \in U(y)\}$ is a compact closed set for each $x \in X$.

Proof. (a) $\rightarrow(\mathrm{b})$ : Let $\mathbb{}\left(\mathbb{5}=\left\{C_{\alpha}: \alpha \in A\right\}\right.$ be a closure-preserving closed cover by compact sets. Put $U(x)=X-\bigcup\left\{C_{\alpha}: x \notin C_{\alpha}\right\}$ for each $x \in X$ and $\mathfrak{u}=\{U(x): x \in X\}$. It is obvious that $\mathfrak{u}$ satisfies (i) and (ii) of (b). Let $y \notin C(x)$ and $z \in U(y)$. Since $x \notin U(y)$ and $U(z) \subset$ $U(y), x \notin U(z)$. Thus, we have $z \notin C(x)$. Therefore $U(y) \cap C(x)=\varnothing$. This proves that each $C(x)$ is closed in $X$. Let $y \in C(x)$. Since $x \in$ $U(y), y \in C_{\alpha}$ whenever $x \in C_{\alpha}$. Thus, $C(x)$ is contained in $\bigcap\left\{C_{\alpha}: x \in C_{\alpha}\right\}$ which is compact and closed. Hence $C(x)$ is a compact closed set for each $x \in X$.

(b) $\rightarrow$ (a): It is obvious from Lemma 2 and (iii) of (b) in this theorem.

REMARK. For a space to have a closure-preserving closed cover by compact sets, R. Telgársky gave, in [12], a sufficient condition which is not necessary.

LEMMA 11. If a first countable space $X$ has a closure-preserving cover by finite sets, then $X$ is developable.

Proof. By Lemma 3, $X$ has an open cover $\mathfrak{A}=\{U(x): x \in X)$ satisfying (i), (ii) and (iii) of $(*)$. So, $X$ has a countable number of open covers $\mathfrak{B}_{n}=\left\{V_{n}(x): x \in X\right\}$ of $X$ such that $\left\{V_{n}(x): n \in N\right\}$ is a local base at $x$ and $V_{n+1}(x) \subset V_{n}(x) \subset U(x)$ for each $x \in X$ and $n \in N$. We shall show that $\left\{\mathfrak{B}_{n}: n \in N\right\}$ is a development of $X$. Let $x \in X$ and let $W$ be an open neighborhood of $x$. There is a finite number of points $x_{1}, \cdots, x_{m} \in X$ such that $\{U \in \mathfrak{I}: x \in U\}=\left\{U\left(x_{1}\right), \cdots, U\left(x_{m}\right)\right\}$. For $i=1, \cdots, m$, we choose some $n_{i} \in N$ such that $V_{n_{i}}\left(x_{i}\right) \subset W$ if 
$x_{i} \in W$ and $x \notin V_{n_{i}}\left(x_{i}\right)$ if $x_{i} \notin W$. Put $n_{0}=\max \left\{n_{i}: i=1, \cdots, m\right\}$. Assume that $x \in V_{n_{0}}(y) \in \mathfrak{B}_{n_{0}}$. By $x \in V_{n_{0}}(y) \subset U(y), y=x_{k}$ for some $k \leqq m$. Since $x \in V_{n_{k}}\left(x_{k}\right), x_{k} \in W$. So, we have $V_{n_{0}}(y) \subset V_{n_{k}}\left(x_{k}\right) \subset W$. Hence St $\left(x, \mathfrak{B}_{n_{0}}\right) \subset W$.

LeMma 12. If a collectionwise Hausdorff, regular space $X$ has a closure-preserving cover by finite sets, then $X$ is paracompact.

The proof of Lemma 12 is quite parallel to that of H. B. Potoczny's theorem in [8]. So, we omit it.

THEOREM 13. If a first countable normal space $X$ has a closurepreserving cover by finite sets, then

(a) $X$ is metrizable under $V=L$ (i.e., the axiom of constructibility), and (b) $X$ is not necessarily metrizable under Martin's Axiom and $2^{\aleph_{0}}>\boldsymbol{\aleph}_{1}$.

Proof. (a): W. Fleissner showed in [2] that a first countable normal space is collectionwise Hausdorff under $V=L$. So, $X$ is paracompact and developable by Lemmas 11 and 12 . Hence $X$ is metrizable.

(b): It is well-known that there is a subset $A$ of the real-line such that every subset of $A$ is a relative $G_{i}$-set, assuming Martin's Axiom plus $2^{\boldsymbol{N}_{0}}>\boldsymbol{\aleph}_{1}$. S. A. Peregudov showed in [6] that Heath's space in [4] (Theorem 3) has the desired property. Here it is to be noted the existence of Heath's space is guaranteed under such an assumption.

THeOREM 14. If a first countable normal space $X$ has a closurepreserving cover by compact sets, then

(a) $X$ is paracompact under $V=L$, and (b) $X$ is not necessarily paracompact under Martin's Axiom and $2^{\boldsymbol{\aleph}_{0}}>\boldsymbol{\aleph}_{1}$.

The proof of (a) of Theorem 14 is similar to that of H. B. Potoczny [8] by using the techniques of W. Fleissner [3]. The detail of the proof is left to the reader. When we consider above Heath's space, (b) is obvious by Lemma 11.

\section{Examples.}

EXAMPle 1. There is a compact $T_{2}$-space which has a closurepreserving cover by finite sets and is not $\sigma$-discrete.

Let $X$ be the one-point-compactification of an uncountable dis- 
crete space. The space $X$ has only one accumulation point $x_{0}$. If $F$ is a closed subset of $X$ such that $x_{0} \notin F$, then $F$ is a finite set. If $D$ is a discrete subset of $X$ such that $x_{0} \in D$, then $D$ is also a finite set. Since $X$ is uncountable, the countable union of discrete closed sets is not $X$. Hence $X$ is not $\sigma$-discrete. It is easily verified that $X$ has a closure-preserving cover consisting of two-point sets.

REMARK. By our Example 1, for a space which has a closurepreserving cover by finite sets, $\sigma$-discreteness is not a necessary condition. Hence the sufficient condition given in our Corollary 7 and R. Telgársky's Theorem 5 in ]12] for such a space is not neccessary.

EXAMPLE 2. There is a paracompact weakly $\sigma$-discrete $T_{2}$-space which is not hereditarily metacompact and not $\sigma$-discrete.

Let $X_{1}=\left\{(x, 0): x \in \boldsymbol{R}^{1}\right\}$ and $X_{2}=\left\{(x, y):(x, y) \in \boldsymbol{R}^{2}, y>0\right\}$. Let $p_{0}=(0,-1)$ and $X=X_{1} \cup X_{2} \cup\left\{p_{0}\right\}$. The topology for the space $X$ is defined as follows: For each $(x, 0) \in X_{1}$ a local base at $(x, 0)$ is $\left\{U_{n}(x, 0): n \in N\right\}$, where $U_{n}(x, 0)=\left\{\left(x^{\prime}, y\right):\left(x^{\prime}-x\right)^{2}+(y-1 / n)^{2}<1 / n^{2}\right\} \cup$ $\{(x, 0)\}$, for each $(x, y) \in X_{2}\{(x, y)\}$ is open in $X$ and a local base at $p_{0}$ is $\left\{X-U_{n_{1}}\left(q_{1}\right) \cup \cdots \cup U_{n_{i}}\left(q_{i}\right) \cup\left\{r_{1}, \cdots, r_{j}\right\}: q_{1}, \cdots, q_{i} \in X_{1}, r_{1}, \cdots\right.$, $r_{j} \in X_{2}$ for each $\left.i, j \in N\right\}$.

It is obvious that $X$ is a weakly $\sigma$-discrete Tychonoff space. Since every open cover of $X$ has a pairwise disjoint open refinement, $X$ is paracompact with $\operatorname{dim} X=0$. It follows from Baire's category theorem that $X_{1} \cup X_{2}$ is not metacompact, which is a well-known fact. By Theorem 1 and Corollary $7, X$ is not $\sigma$-discrete.

REMARK. Our Example 2 shows that we can not replace hereditary metacompactness in Theorem 1 by metacompactness and that the necessary condition in Corollary 8 proved by $R$. Telgársky is not sufficient.

EXAMPLE 3. There is a metacompact $\sigma$-discrete normal space which is not paracompact.

Let $G$ be Bing's space modified by E. Michael in [5] (Example 2). We define $F_{p}$ as in [1] (Example $H$ ). Then the space $G$ is perfectly normal, metacompact, and non-paracompact ([5]). Since every point of $G-F_{p}$ is an isolated point of $G$ and the discrete closed subset $F_{p}$ is a $G_{\tilde{\delta}}$-set, $G$ is $\sigma$-discrete. 


\section{REFERENCES}

1. R. H. Bing, Metrization of topological spaces, Canad. J. Math., 3 (1951), 175-186.

2. W. Fleissner, Normal Moore spaces in the constructible universe, Proc. Amer. Math. Soc., 46 (1974), 294-298.

3. - Application of collectionwise Hausdorff, Studies in Topology, Academic Press, (1975).

4. R. W. Heath, Screenable, pointwise paracompactness and metrization of Moore spaces, Canad. J. Math., 16 (1964), 763-770.

5. E. Michael, Point-finite and locally finite covers, Canad. J. Math., 7 (1955), 275-279.

6. S. A. Peregudov, On normal spaces which admit a closure-preserving covering by bicompact sets, (in Russian), Vestnik. Moskow. Univ., 5 (1974), 40-42.

7. H. B. Potoczny, A non-paracompact space which admits a closure-preserving cover of compact sets, Proc. Amer. Math. Soc., 32 (1972), 309-311.

8. Closure-preserving families of compact sets, General Topology and Appl., 3 (1973), 243-248.

9. __ Closure-preserving families of finite sets, Fund. Math., 86 (1975), 173-176.

10. H. Tamano, A characterization of paracompactness, Fund. Math., 72 (1971), 189-201.

11. R. Telgársky, Concerning two covering properties, Collq. Madh., (to appear).

12. - Closure-preserving covers, Fund. Math., 75 (1974), 165-175.

13. - Spaces defined by topological games, Fund. Math., 88 (1975), 193-223.

14. Y. Yajima, A note on spaces which have closure-preserving covers by finite sets, Bull. Acad. Polon. Sci. Sér. Sci. Math. Astr. Phys., 24 (1976), 611-614.

Received May 31, 1976 and in revised form November 17, 1976.

UNIVERSITY OF TSUKUBA

IBARAKI 300-31, JAPAN 


\section{PACIFIC JOURNAL OF MATHEMATICS}

\section{EDITORS}

RICHARD ARENS (Managing Editor)

University of California

Los Angeles, CA 90024

R. A. BEAUMONT

University of Washington

Seattle, WA 98105

C. C. Moore

University of California

Berkeley, CA 94720

\section{J. DugundJI}

Department of Mathematics

University of Southern California

Los Angeles, CA 90007

R. Finn and J. Milgram

Stanford University

Stanford, CA 94305

\section{ASSOCIATE EDITORS}

\section{E. F. BECKENBACH}

B. H. NEUMANN

F. WoLF

K. YOSHIDA

\section{SUPPORTING INSTITUTIONS}

\author{
UNIVERSITY OF BRITISH COLUMBIA \\ CALIFORNIA INSTITUTE OF TECHNOLOGY \\ UNIVERSITY OF CALIFORNIA \\ MONTANA STATE UNIVERSITY \\ UNIVERSITY OF NEVADA \\ NEW MEXICO STATE UNIVERSITY \\ OREGON STATE UNIVERSITY \\ UNIVERSITY OF OREGON \\ OSAKA UNIVERSITY
}

\author{
UNIVERSITY OF SOUTHERN CALIFORNIA \\ STANFORD UNIVERSITY \\ UNIVERSITY OF HAWAII \\ UNIVERSITY OF TOKYO \\ UNIVERSITY OF UTAH \\ WASHINGTON STATE UNIVERSITY \\ UNIVERSITY OF WASHINGTON \\ AMERICAN MATHEMATICAL SOCIETY
}

The Supporting Institutions listed above contribute to the cost of publication of this Journal, but they are not owners or publishers and have no responsibility for its content or policies.

Mathematical papers intended for publication in the Pacific Jaurnal of Mathematics should be in typed form or offset-reproduced, (not dittoed), double spaced with large margins. Please do not use built up fractions in the text of your manuscript. You may however, use them in the displayed equations. Underline Greek letters in red, German in green, and script in blue. The first paragraph or two must be capable of being used separately as a synopsis of the entire paper. Items of the bibliography should not be cited there unless absolutely necessary, in which case they must be identified by author and Journal, rather than by item number. Manuscripts, in triplicate, may be sent to any one of the editors. Please classify according to the scheme of Math. Reviews, Index to Vol. 39. All other communications should be addressed to the managing editor, or Elaine Barth, University of California, Los Angeles, California, 90024.

The Pacific Journal of Mathematics expects the author's institution to pay page charges, and reserves the right to delay publication for nonpayment of charges in case of financial emergency

100 reprints are provided free for each article, only if page charges have been substantially paid. Additional copies may be obtained at cost in multiples of 50 .

The Pacific Journal of Mathematics is issued monthly as of January 1966. Regular subscription rate: $\$ 7200$ a year (6 Vols., 12 issues). Special rate: $\$ 36.00$ a year to individual members of supporting institutions.

Subscriptions, orders for back numbers, and changes of address should be sent to Pacific Journal of Mathematics, 103 Highland Boulevard, Berkeley, California, 94708.

PUBLISHED BY PACIFIC JOURNAL OF MATHEMATICS, A NON-PROFIT CORPORATION

Printed at Kokusai Bunken Insatsusha (International Academic Printing Co., Ltd.). 8-8, 3-chome, Takadanobaba, Shinjuku-ku, Tokyo 160, Japan.

Copyrit (C) 1975 by Pacific Journal of Mathematics Manufactured and first issued in Japan 


\section{Pacific Journal of Mathematics \\ Vol. 69, No. $2 \quad$ June, 1977}

Carol Alf and Thomas Alfonso O'Connor, Unimodality of the Lévy spectral

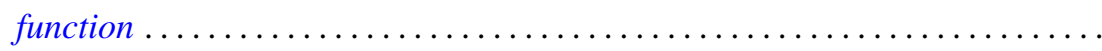

S. J. Bernau and Howard E. Lacey, Bicontractive projections and reordering of

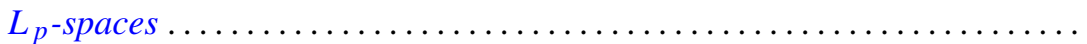

Andrew J. Berner, Products of compact spaces with bi-k and related spaces..... 303

Stephen Richard Bernfeld, The extendability and uniqueness of solutions of ordinary differential equations ...............................

Marilyn Breen, Decompositions for nonclosed planar m-convex sets ..........

Robert F. Brown, Cohomology of homomorphisms of Lie algebras and Lie

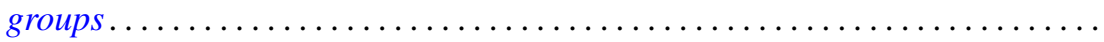

Jack Douglas Bryant and Thomas Francis McCabe, A note on Edelstein's iterative test and spaces of continuous functions ....................

Victor P. Camillo, Modules whose quotients have finite Goldie dimension ....... 333

David Downing and William A. Kirk, A generalization of Caristi's theorem with

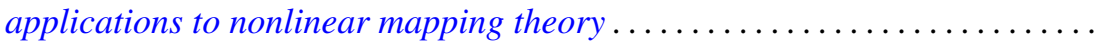

Daniel Reuven Farkas and Robert L. Snider, Noetherian fixed rings ...........

Alessandro Figà-Talamanca, Positive definite functions which vanish at

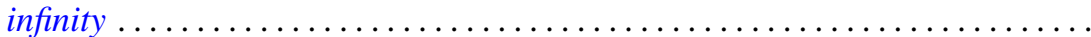

Josip Globevnik, The range of analytic extensions .................. 365

André Goldman, Mesures cylindriques, mesures vectorielles et questions de

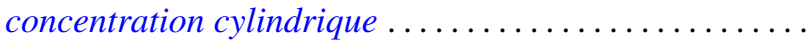

Richard Grassl, Multisectioned partitions of integers..........

Haruo Kitahara and Shinsuke Yorozu, A formula for the normal part of the

Laplace-Beltrami operator on the foliated manifold .... .

Marvin J. Kohn, Summability $R_{r}$ for double series .........

Charles Philip Lanski, Lie ideals and derivations in rings with involution ..

Solomon Leader, A topological characterization of Banach contractions . .

Daniel Francis Xavier O’Reilly, Cobordism classes of fiber bundles . .

James William Pendergrass, The Schur subgroup of the Brauer group . .

Howard Lewis Penn, Inner-outer factorization of functions whose Fourier series

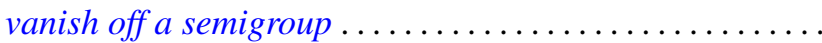

501

William T. Reid, Some results on the Floquet theory for disconjugate definite

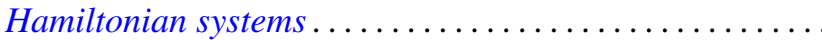

Caroll Vernon Riecke, Complementation in the lattice of convergence

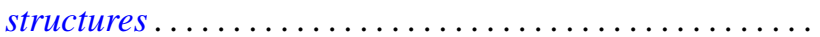

Louis Halle Rowen, Classes of rings torsion-free over their centers ......... 527

Manda Butchi Suryanarayana, A Sobolev space and a Darboux problem ....... 535

Charles Thomas Tucker, II, Riesz homomorphisms and positive linear maps.... 551

William W. Williams, Semigroups with identity on Peano continua ........... 557

Yukinobu Yajima, On spaces which have a closure-preserving cover by finite 